\title{
NOTES
}

\section{Synthesis of Polyurethanes Containing a Dicyanovinyl Group and Thermal Properties}

\author{
Jin-Seok KIm, Seung-Hyun ChoI, Sang-Tae KIm, \\ and Myoung Seon GoNG \\ Department of Chemistry, Dankook University, \\ Cheonan 330-714, Chungnam, Korea
}

(Received December 21, 1992)

\begin{abstract}
KEY WORDS Enaminonitriles / Polyurethane / Thermally Curable Polymer / Dicyanovinyl Group / Thermally Stable Polymer /
\end{abstract}

A close analogy of chemical reactivity between dicyanovinylidine group $\left(=\mathrm{C}(\mathrm{CN})_{2}\right)$ and carbonyl group has been proposed by Wallenfels. ${ }^{1,2}$

Dicyanovinyl chloride is readily attacked by nucleophiles and the resulting carbanion enhances expulsion of chloride anions by mesomeric electron donation of the cyano group. ${ }^{3,4)}$

1-Chloro-2,3-dicyanoethene (1) is reactive toward nucleophiles such as water, alcohols, and amines. 1-Chloro-1-phenyl-2,2-dicyanoethene (2) reacts only with amine group of aminol to form the alcohol derivatives containing enaminonitrile moiety. ${ }^{5}$

Poly(enaminonitrile)s $\mathrm{s}^{6-11}$ and poly(enaryloxynitrile)s ${ }^{12}$ prepared from $p$-bis(1-chloro2,2-dicyanovinyl)benzene (3) with diamines and aromatic diols showed good thermal stability after curing without releasing of volatile byproduct.

Polyurethane which undergoes heat curing has become a subject of considerable interest. We previously reported that $p$-bis $[1-[N$ methyl-( $N$-hydroxyethyl)amino]-2,2-dicyanovinyl]benzene (4) containing enaminonitrile unit was polymerized with diisocyanates and the resulting polyurethanes showed good thermal stability. ${ }^{5}$
In this paper, polyurethanes with dicyanovinyl group, which is partially distributed in the main chain of polymer back bone, are prepared by the copolymerization of diisocyanates with 4 and 1,4-butanediol and their thermal properties are investigated.

\section{EXPERIMENTAL}

p-Bis(1-chloro-2,2-dicyanovinyl)benzene was synthesized by the method previously reported. $^{8}$ 1,4-Butanediol, diphenylmethane4,4'-diisocyanate (MDI), hexamethylenediisocyanate (HDI), and tolylene-2,4-diisocyanate (TDI) were purified by conventional purification method. $\quad N$-Methyl-2-pyrrolidinone (N-MP) and triethylamine were purified by drying over calcium hydride and distillation.

IR spectra were taken on a Perkin-Elmer Model 1310 spectrometer and ${ }^{1} \mathrm{H}$ NMR spectra were recorded on a Bruker Am-300 spectrometer. Size exclusion chromatography data were obtained by Waters HPLC using three columns ( $\mu$-Styragel $10^{2}, 10^{3}$, and $10^{4} \AA$ ) in $\mathrm{THF}$ at $25^{\circ} \mathrm{C}$, and calibrated with polystyrene standard. Elemental analyses were obtained with a Yanaco MT-3, CHN-Analyzer. Thermal analyses were performed with a Mettler thermal analyzer at a heating rate of 
$10^{\circ} \mathrm{C} \mathrm{min}^{-1}$ in nitrogen.

Representative Polymerization of Diisocyanate with 1,4-Butanediol and 4

A solution of $1 \mathrm{~g}(2.9 \mathrm{mmol})$ of 4 and $0.26 \mathrm{~g}$ (2.9 mmol) of 1,4-butanediol in $10 \mathrm{ml}$ of N-MP was added to a mixture of $3.7 \mu 1(0.01 \mathrm{mmol})$ of triethylamine and $1.40 \mathrm{~g}(5.8 \mathrm{mmol})$ of MDI in $5 \mathrm{ml}$ of N-MP in nitrogen atmosphere. The temperature was raised to $70^{\circ} \mathrm{C}$ and maintained for 2 hours. The resulting yellow solution was poured into a large amount of methanol to precipitate the polymer. The precipitate was filtered and dried in vacuo $\left(0.1\right.$ Torr) at $80^{\circ} \mathrm{C}$ for 12 hours.

Similar procedures were followed by the polymerization of different compositions of $\mathbf{4}$ and 1,4-butanediol units in the polyurethane.

8 Yield 95\%.

IR (KBr): 3317, 2953, 2210, 1712, 1527, 1222, and $1100 \mathrm{~cm}^{-1}$.

${ }^{1} \mathrm{H}$ NMR (DMSO- $d_{6}$ ): $9.3(\mathrm{~s}, 2 \mathrm{H}, 2 \mathrm{~N} \underline{\mathrm{H}}$ ), $7.1-7.8(\mathrm{~m}, 10 \mathrm{H}$, aromatic $\mathrm{H}$ 's in $\mathrm{MDI}$ and $1 / 2$ 4), $4.0\left(\mathrm{~m}, 6 \mathrm{H}, 2-\mathrm{O}-\mathrm{CH}_{2}-\mathrm{CH}_{2}-\mathrm{N}-\mathrm{CH}_{3}\right.$ and $\left.1 / 2-\mathrm{OCH}_{2} \mathrm{CH}_{2} \mathrm{CH}_{2} \mathrm{CH}_{2}-\mathrm{O}-\right), 3.6-3.3$ (m, 5H, $\left.-\underline{\mathrm{CH}}_{2}-\mathrm{N}-\mathrm{C}_{3}\right), 2.2(\mathrm{~s}, 2 \mathrm{H}, 1 / 2$ $-\mathrm{O}-\mathrm{CH}_{2} \mathrm{CH}_{2} \mathrm{CH}_{2} \mathrm{CH}_{2}-\mathrm{O}-$ ).

Anal. Calcd for $\left(\mathrm{C}_{27} \mathrm{H}_{25} \mathrm{~N}_{5} \mathrm{O}_{4}\right): \mathrm{C}, 67.08 \%$, H, 5.18\%; N, $14.49 \%$. Found: C, $66.02 \%$; $5.07 \% ; \mathrm{N}, 13.91 \%$.

11 Yield 89\%.

IR (KBr): 3319, 2955, 2208, 1722, 1550, 1226, and $1064 \mathrm{~cm}^{-1}$.

${ }^{1} \mathrm{H}$ NMR (DMSO- $d_{6}$ ): 9.5 (s, 2H, $2-\mathrm{N} \underline{\mathrm{H}}-$ ), $7.1-7.8(\mathrm{~m}, 5 \mathrm{H}$, aromatic H's in TDI and $1 / 2$ 4), $4.0-4.2\left(\mathrm{~m}, 6 \mathrm{H}, 2-\mathrm{O}-\mathrm{CH}_{2} \mathrm{CH}_{2}-\mathrm{NCH}_{3}\right.$ and $\left.1 / 2-\mathrm{OCH}_{2} \mathrm{CH}_{2} \mathrm{CH}_{2} \mathrm{CH}_{2} \mathrm{O}-\right), 3.5-3.8(\mathrm{~m}$, $\left.5 \mathrm{H},-\mathrm{CH}_{2}-\mathrm{NC}_{3}\right), 3.0\left(\mathrm{~s}, 3 \mathrm{H}, \mathrm{ph}-\mathrm{CH}_{3}\right), 2.0$ (m, $2 \mathrm{H}, 1 / 2-\mathrm{O}-\mathrm{CH}_{2} \mathrm{CH}_{2} \mathrm{CH}_{2} \mathrm{CH}_{2} \mathrm{O}-$ ).

Anal. Calcd for $\left(\mathrm{C}_{20} \mathrm{H}_{21} \mathrm{~N}_{5} \mathrm{O}_{4}\right)_{n}: \mathrm{C}, 60.76 \%$; $\mathrm{H}, 5.32 \%$; N, $17.72 \%$. Found: C, $60.37 \%$; $5.17 \% ; \mathrm{N}, 17.48 \%$.

12 Yield $87 \%$.

IR (KBr): 3358, 2937, 2780, 2270, 1712, 1556, 1440,1249 , and $1138 \mathrm{~cm}^{-1}$.

${ }^{1} \mathrm{H}$ NMR (DMSO- $d_{6}$ ): 9.0 (s, 2H, $2-\mathrm{N} \underline{\mathrm{H}}-$ ),
7.0-7.6 (m, 2H, 1/2 aromatic H's in 4), 4.0 (m, $6 \mathrm{H}, 2-\mathrm{O}-\mathrm{CH}_{2} \mathrm{CH}_{2}-\mathrm{N}-\mathrm{CH}_{3}$ and $1 / 2$ $\left.-\mathrm{OC}_{2} \mathrm{CH}_{2} \mathrm{CH}_{2} \mathrm{CH}_{2} \mathrm{O}-\right), 3.0-3.8(\mathrm{~m}, 9 \mathrm{H}$, $-\mathrm{CH}_{2} \mathrm{NCH}_{3}$ and $-\mathrm{HNC} \underline{\mathrm{H}}_{2}-\left(\mathrm{CH}_{2}\right)_{4}-\mathrm{CH}_{2}-$ $\mathrm{NH}-), 2.0\left(\mathrm{~m}, 10 \mathrm{H}, 1 / 2-\mathrm{O}-\mathrm{CH}_{2} \mathrm{C}_{2} \mathrm{CH}_{2}-\right.$ $\mathrm{CH}_{2}-\mathrm{O}-$ and $\left.-\mathrm{HNCH}_{2}-\left(\mathrm{CH}_{2}\right)_{4}-\mathrm{CH}_{2}-\mathrm{NH}-\right)$.

Anal. Calcd for $\left(\mathrm{C}_{20} \mathrm{H}_{27} \mathrm{~N}_{5} \mathrm{O}_{4}\right)_{n}: \mathrm{C}, 59.85 \%$; $\mathrm{H}, 6.73 \%$; N, $17.46 \%$. Found: C, $58.92 \%$; H, $6.29 \% ; \mathrm{N}, 17.23 \%$.

\section{RESULTS AND DISCUSSION}

Diol monomer, $p$-bis[1-[N-methyl- $N$-(hydroxyethyl)amino]-2,2-dicyanovinyl]benzene (4) was prepared by reacting $p$-bis(1-chloro2,2-dicyanovinyl)benzene (3) with 2-( $N$-methylamino)ethanol.

Preparation of model compound, 5, from phenylisocyanate was performed to demonstrate the feasibility of polymerization and obtain a model urethane compound for the characterization of polymers.
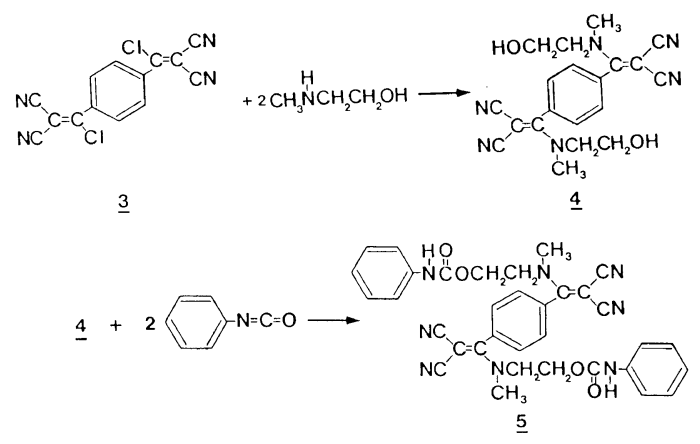

The polymerization of different contents of 4 and 1,4-butanediol with diisocyanates such as MDI, HDI, and TDI was attempted to obtain a controlled amount of enaminonitrile unit in the main chain of polyurethane.

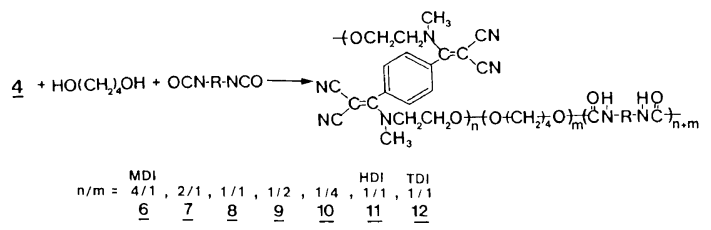

The conditions and results of copolymerization of 1,4-butanediol and 4 with diisocyanates 
Table I. Results of polymerizations of $\mathbf{4}$ and 1,4-butanediol with diisocyanates

\begin{tabular}{cccccc}
\hline & & & \multicolumn{3}{c}{ Yield } \\
Polymer & & & \\
& & & & & \\
& & & & & \\
& & & & & \\
\hline $\mathbf{6}$ & $1 / 4$ & MDI & 96 & 0.31 & 12,800 \\
$\mathbf{7}$ & $1 / 2$ & MDI & 97 & 0.23 & 11,200 \\
$\mathbf{8}$ & $1 / 1$ & MDI & 95 & 0.34 & 21,000 \\
$\mathbf{9}$ & $2 / 1$ & MDI & 95 & 0.26 & 11,800 \\
$\mathbf{1 0}$ & $4 / 1$ & MDI & 95 & 0.21 & 8,400 \\
$\mathbf{1 1}$ & $1 / 1$ & HDI & 87 & 0.19 & 7,420 \\
$\mathbf{1 2}$ & $1 / 1$ & TDI & 85 & 0.27 & 12,400
\end{tabular}

a Polymerizations were performed at $70^{\circ} \mathrm{C}$ for 2 hours in all cases.

b Measured in $N, N$-dimethylformamide in $1 \mathrm{~g} \mathrm{dl}^{-1}$ at $25^{\circ} \mathrm{C}$.

c Weight average molecular weights were obtained with Waters HPLC in tetrahydrofuran and calibrated with polystyrene standard.

are summarized in Table I.

Polyurethanes, 6-12, were obtained by solution polymerization in $N$-methyl-2-pyrrolidinone at $70^{\circ} \mathrm{C}$ for 2 hours. The yellow powdery polymers were obtained after precipitation into methanol in good yield. The chemical structures of copolymers were characterized by spectroscopies.

In the case of IR spectrum of polymer with the same content of $\mathbf{4}$ and 1,4-butanediol units, characteristic bands at 3320, 2210, 1710, 1530, and $1220-1100 \mathrm{~cm}^{-1}$ assignable to $\mathrm{N}-\mathrm{H}$, $\mathrm{C} \equiv \mathrm{N}, \mathrm{C}=\mathrm{O}, \mathrm{C}=\mathrm{C}$, and $\mathrm{C}-\mathrm{O}$, respectively, appeared.

Compared to the IR spectra of polymers with different contents of 4 and 1,4-butanediol, as the component of $\mathbf{4}$ in polymer increased, the intensity of the $\mathrm{C} \equiv \mathrm{N}$ stretching band at $2210 \mathrm{~cm}^{-1}$ in contrast to $\mathrm{C}=\mathrm{O}$ band at $1710 \mathrm{~cm}^{-1}$ increased.

${ }^{1} \mathrm{H}$ NMR spectrum showed aromatic protons of a fragment of 4 at $7.8 \mathrm{ppm}$, whereas those of MDI appeared at $7.1-7.5 \mathrm{ppm}$ as a multiplet. The higher content of 1,4-butanediol unit in polymer exhibited the gradual increase of methylene protons at $2 \mathrm{ppm}$. The proposed structure of polymer was also confirmed by

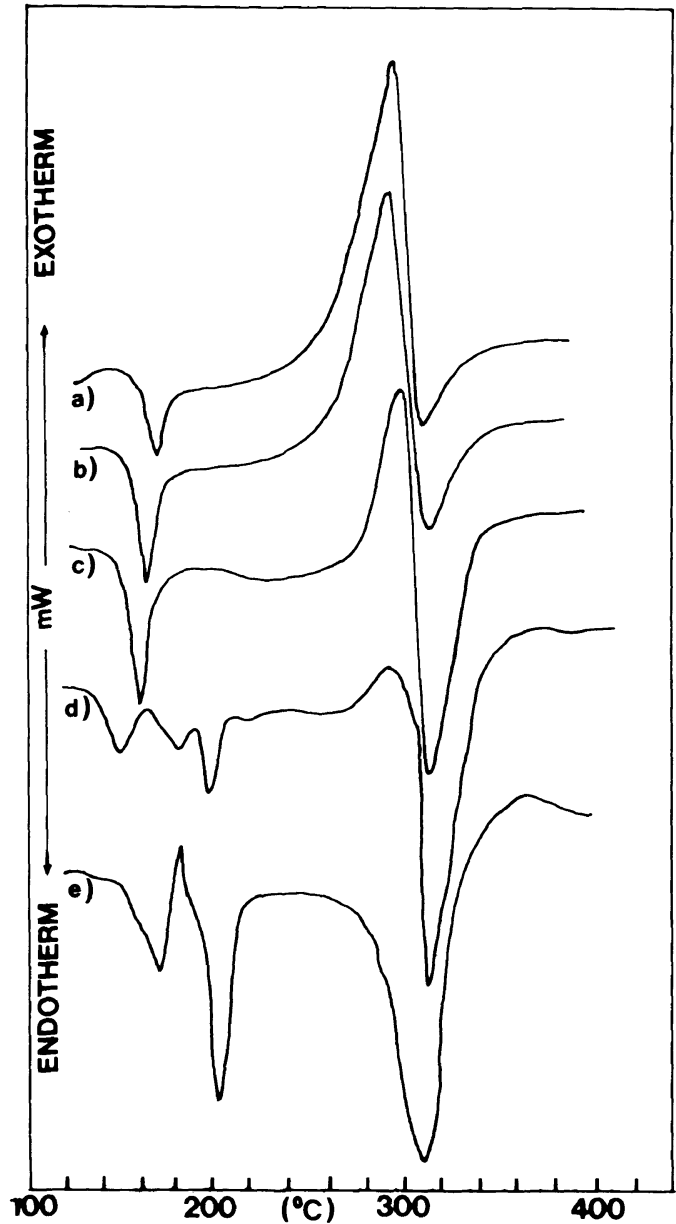

Figure 1. DSC thermograms of polyurethanes, a) 6, b) 7, c) 8, d) 9, and e) 10, obtained from 4 and 1,4-butanediol with MDI at a heating rate of $10^{\circ} \mathrm{C} \mathrm{min}^{-1}$ in nitrogen.

elemental analysis. The spectroscopic data of other polyurethanes obtained from TDI and HDI matched well with the corresponding chemical structures.

Polyurethanes, 6-12 exhibit good solubility in common organic solvents such as DMF, DMSO, acetonitrile and THF, and slightly soluble in methylene chloride and acetone. After these polymers have been heated near the temperature of exotherm, they are no longer soluble or are reduced in solubility in the solvent for the untreated polymers.

The polymers appeared to possess an in- 
herent viscosity of $0.2-0.3$, and $M_{n}=3,800$ 5,200 and $M_{w}=8,600-21,000$. These are not high molecular weights judging from the size exclusion chromatography data. When the film was cast from the DMF solution of polymer after evaporation of solvent, the clear and tough film was formed.

In DSC thermograms as shown in Figure 1, polyurethanes 6,7 , and 8 showed a endotherm at $170^{\circ} \mathrm{C}, 162^{\circ} \mathrm{C}$, and $160^{\circ} \mathrm{C}$, respectively, which corresponds to the melting of polymer. Higher transition temperatures were observed for the polymer incorporating more than 4 units.

In the case of polymers, 9 and $\mathbf{1 0}$, three or two consecutive endotherms appeared. This might be due to the liquid crystalline behavior of the polymer.

The polymers except 10 exhibit large

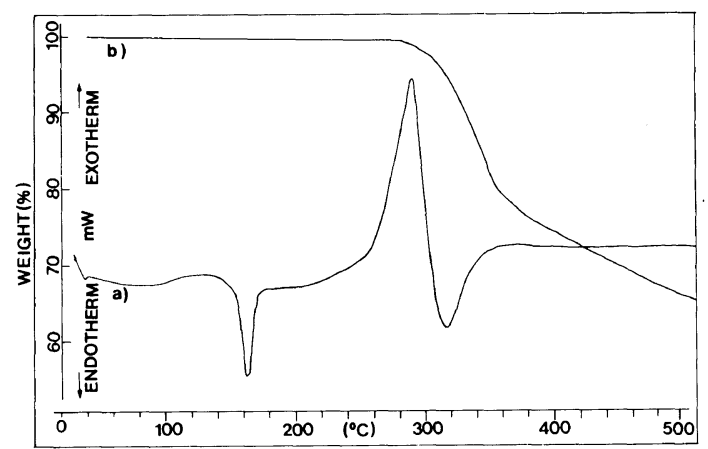

Figure 2. (a) DSC thermogram and (b) TGA trace of polyurethane, 6 . exothermic peaks at $290^{\circ} \mathrm{C}$ and endothermic peak at $320^{\circ} \mathrm{C}$. As the content of 4 in polymer increased, exothermic peak intensity increased and endothermic peak intensity decreased. In the case of polymer 10, a large endotherm appeared alone at $320^{\circ} \mathrm{C}$. At the temperature of the exotherm, slight weight loss was detected and a sudden weight loss begun at $320^{\circ} \mathrm{C}$.

Thermogravimetric analysis of polymers are shown in Figure 2 and the data are summarized in Table II. Any detectable loss of weight is not observed at the beginning of a large exotherm temperature. This indicates that the polyurethanes containing dicyanovinyl group were cured without decomposition or elimination of volatile a byproduct.

The polymers showed a $10 \%$ weight loss in nitrogen over a temperature range of 300 $320^{\circ} \mathrm{C}$ and gave a weight residual varing from $40-66 \%$ at a temperature of $500^{\circ} \mathrm{C}$. The higher content of 4 in the polymer showed greater thermal stability than those with higher content of 1,4-butanediol. Within each series, greater thermal stability was associated with the content of enaminonitrile units in the polymer. In addition, all polymers displayed rapid change at the temperature of exotherm in the IR spectra. The urethane $\mathrm{N}-\mathrm{H}, \mathrm{C} \equiv \mathrm{N}$, and $\mathrm{C}=\mathrm{O}$ bands at 3330,2210 , and $1710 \mathrm{~cm}^{-1}$ disappeared gradually and the bands at 1520 $1580 \mathrm{~cm}^{-1}$, characteristic $\mathrm{C}=\mathrm{N}$ bands, appeared as illustrated in Figure 3.

In the curing mechanism, poly(enaminoni-

Table II. Thermal properties of polyurethanes obtained from 4 and 1,4-butanediol with diisocyanates

\begin{tabular}{|c|c|c|c|c|c|c|}
\hline \multirow{2}{*}{ Polymer } & \multirow{2}{*}{$1,4-\mathrm{BD} / 4$} & \multirow{2}{*}{$\frac{T_{m}}{{ }^{\circ} \mathrm{C}}$} & \multirow{2}{*}{$\frac{\text { Exo }}{{ }^{\circ} \mathrm{C}}$} & \multirow{2}{*}{$\frac{\text { Endo }}{{ }^{\circ} \mathrm{C}}$} & \multicolumn{2}{|c|}{ Residual weight $/ \%$} \\
\hline & & & & & $400^{\circ} \mathrm{C}$ & $500^{\circ} \mathrm{C}$ \\
\hline 6 & $1 / 4$ & 170 & 295 & 308 & 74 & 56 \\
\hline 7 & $1 / 2$ & 162 & 291 & 310 & 69 & 62 \\
\hline 8 & $1 / 1$ & 160 & 298 & 312 & 57 & 51 \\
\hline 9 & $2 / 1$ & $150,184,197$ & 295 & 310 & 50 & 40 \\
\hline 10 & $4 / 1$ & 169,205 & - & 310 & 47 & 35 \\
\hline 11 & $1 / 1$ & 140 & 302 & 370 & 55 & 42 \\
\hline 12 & $1 / 1$ & - & 300 & 320 & 63 & 52 \\
\hline
\end{tabular}




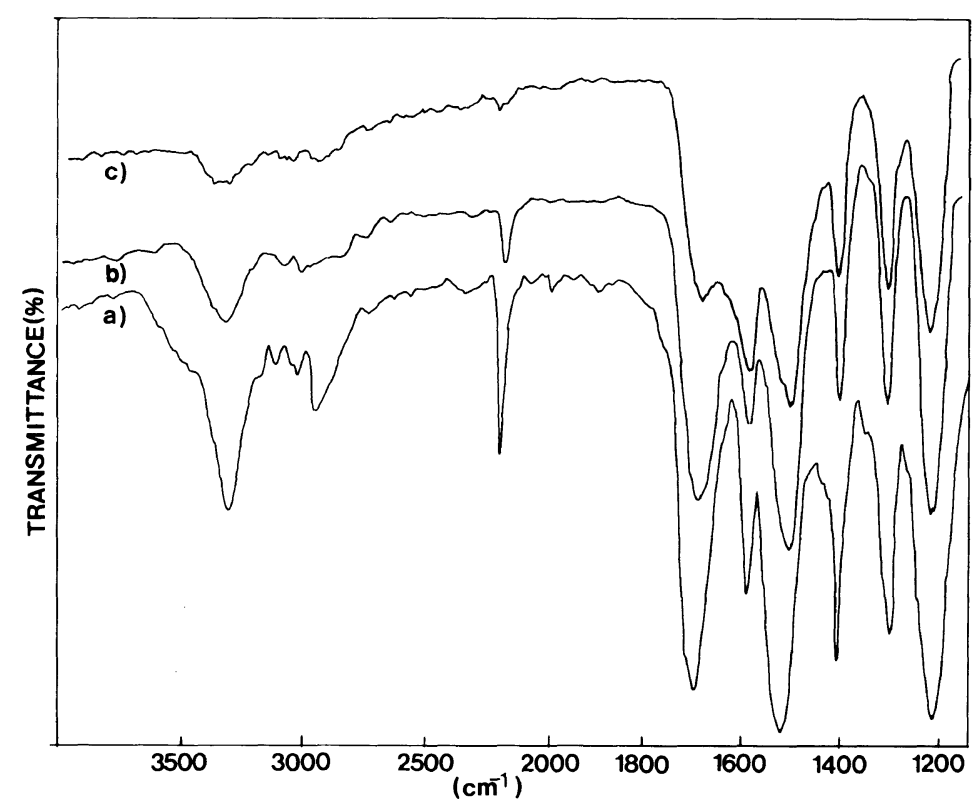

Figure 3. Superimposed IR spectra of polyurethane, 8, after (a) $0 \mathrm{~h}$, (b) $0.5 \mathrm{~h}$, and (c) $1 \mathrm{~h}$ at $265^{\circ} \mathrm{C}$ under nitrogen.

trile)s undergo intramolecular cyclization to polyquinoline. ${ }^{6-8}$ However, curing reactions of polyurethanes are assumed to proceed largely by intermolecular addition of the dicyanovinyl group. ${ }^{12}$ Upon comparison with poly(enaminonitrile)s ${ }^{8}$ and poly(enaryloxynitrile)s, ${ }^{13}$ polymers $6-12$ showed less thermal stability, probably due to the presence of aliphatic hydrocarbon units in the chain.

\section{REFERENCES}

1. K. Wallenfels, Chemia, 20, 303 (1966).

2. K. Wallenfels, K. Friedrich, J. Rieser, and W. Ertel, Angew. Chem., Int. Ed. Engl., 15, 261 (1976).

3. Z. Rappoport and R. Ta-Shma, J. Chem. Soc., B. 871 (1971).

4. Z. Rappoport and A. Topol, J. Chem. Soc., Perkin
Trans. 2, 1823 (1972).

5. M. S. Gong, H. S. Moon, and S. T. Kim, Macromolecules, 25, 7392 (1992).

6. J. A. Moore and D. R. Robello, Polym. Prepr. Am. Chem. Soc., Div. Polym. Chem., 27(2), 127 (1986).

7. J. A. Moore and D. R. Robello, Macromolecules, 19, 2667 (1986).

8. J. A. Moore and D. R. Robello, Macromolecules, 22, 1084 (1989).

9. J. A. Moore and P. G. Mehta, Polym. Mater. Sci. Eng., 63, 351 (1990).

10. J. A. Moore and P. G. Mehta, Polym. Mater. Sci. Eng., 64, 835 (1991).

11. M. S. Gong, J. O. Lee, and S. T. Kim, Polymer (Korea), 15, 95 (1991).

12. G. B. Buttler and J. E. Kresta, "Cyclopolymerization and Polymers with Chain-Ring Structures," ACS Symp. Ser. 195, American Chemical Society, Washington D.C., 1982, pp 285-295.

13. H. S. Moon, S. T. Kim, and M. S. Gong, Makromol. Chem. Rapid Commun., 12, 591 (1991). 